\title{
Intracortical Axonal Projections of Lamina VI Cells of the Primary Somatosensory Cortex in the Rat: A Single-Cell Labeling Study
}

\author{
Zhong-Wei Zhang and Martin Deschênes \\ Centre de Recherche Université Laval-Robert Giffard, Hôpital Robert Giffard, Québec City, Québec G1J 2G3, Canada
}

\begin{abstract}
A sample of 84 neurons in lamina Vla of rat somatosensory cortex (S1) was juxtacellularly labeled with biocytin, and the axons of the neurons were traced. Three classes of cells were identified as corticothalamic, corticocortical, and local circuit neurons. Corticothalamic cells (46\%) are small, short pyramids projecting either to the ventral posteromedial nucleus alone or to the posterior group as well. The former are in upper lamina $\mathrm{VI}$, have apical dendrites terminating in layer IV, and have intracortical collaterals ascending to layer IV as a narrow column about the size of a barrel. The latter are in the lower half of lamina VI, have apical dendrites terminating in layer $\mathrm{V}$, and have a more extensive network of collaterals terminating in the upper part of lamina V. Corticothalamic cells do not project to distant cortical targets through branching axons. Corticocortical cells (44\%) are small, short pyramids, inverted or modified pyramids,
\end{abstract}

or bipolar spiny neurons. They send collaterals principally to infragranular layers of S1 and branches to the second somatosensory cortex, the motor cortex, or the corpus callosum. Local circuit neurons (10\%) are basket cells, concentrated in upper lamina $\mathrm{VI}$, having smooth, beaded dendrites and a rich collateral network densely covered with varicosities in layers $\mathrm{V}$ and VI. We conclude that (1) dendritic morphology and axonal arborizations of corticothalamic cells relate to the projection target; (2) many apparently diverse layer VI cells project to other cortical fields; and (3) lamina $\mathrm{VI}$ is a network for corticothalamic and corticocortical communication.

Key words: corticothalamic cells; corticocortical cells; short pyramidal cells; cortical barrel field; ventral posteromedial nucleus; posterior thalamic group
Anatomical studies have shown that all neocortical areas establish reciprocal connections with the thalamus (Jones, 1985). A remarkable feature of this relationship is that the number of corticothalamic (CT) cells in any cortical region exceeds by far the population of thalamocortical neurons that project to that particular region. In lamina V I of the cat primary visual cortex, for instance, their number exceeds by one order of magnitude the population of thalamocortical cells found in the lateral geniculate nucleus (Koch and Sherman, 1988). It seems doubtful that such a large number of cells would only serve to modulate the transmission of sensory inputs through the thalamus. Understanding the numerical importance of CT cells thus seems crucial for the elaboration of any realistic model of thalamocortical functions (for review, see Sherman and Guillery, 1996). As a first step in this direction, it is mandatory first to establish the fine anatomical organization of these pathways.

Data obtained from measurements in the rat brain show that lamina VI is one of the layers with highest cell density (Miller and Potempa, 1990). The most numerous cells are the small pyramids that possess a short apical dendrite that ends in lamina IV. A large number of these neurons give rise to CT axons, but retrograde tracer studies have also revealed a number of lamina VI cells with ipsilateral corticocortical projections to distant cortical fields or to the claustrum (Zilles and Wree, 1995; Sherk, 1986). Lamina VI is also characterized by the polymorphism of its cell

\footnotetext{
Received March 26, 1997; revised May 15, 1997; accepted May 23, 1997.

This work was supported by a grant from the Medical Research Council of Canada.

Correspondence should be addressed to Dr. Martin Deschênes, Centre de Recherche Université Laval-Robert Giffard, 2601 de la Canardière, F-6500, Québec City, Québec G1J 2G3, Canada.

Copyright (C) 1997 Society for Neuroscience $0270-6474 / 97 / 176365-15 \$ 05.00 / 0$
}

population, which includes inverted and modified pyramids, spiny bipolar cells, tangential neurons, small and large fusiform cells, and Martinotti cells (see Tömböl, 1984). At present, however, there exists very little information concerning the axonal projections of these neurons.

Recent studies in which a few individual axons were filled with biocytin provided evidence of the existence of three classes of CT cells in the infragranular layers of the somatosensory and visual cortices of the rat (Bourassa and Deschênes, 1995; Bourassa et al., 1995; Lévesque et al., 1996). These three classes of cells include some layer V cells and two populations of neurons within layer VI that are characterized by a different distribution of their axons in the thalamus. The labeling of small pools of cells, however, rarely allows the identification of the cell of origin of each axon and the mapping of its local net of collaterals. To characterize further the neuronal architecture of CT cells, we took advantage of the juxtacellular method that was recently developed for labeling single neurons in vivo (Pinault, 1996).

The present study had two main objectives: (1) to determine whether the two subpopulations of CT cells in lamina VI of the cortical barrel field display differences in the intracortical distribution of their dendritic and axonal processes, and (2) to better characterize the axonal projection patterns of the other cell types that are colocalized with CT cells in lamina VI of the rat primary somatosensory cortex.

\section{MATERIALS AND METHODS}

Labeling protocol. Experiments were performed in 35 adult rats (Sprague Dawley) under ketamine $(75 \mathrm{mg} / \mathrm{kg})$ plus xylazine $(5 \mathrm{mg} / \mathrm{kg})$ anesthesia. Housing and treatment conditions adhered to federally prescribed and university animal care and use guidelines. Single-cell juxtacellular labeling was made according to the method described by Pinault (1996), using 


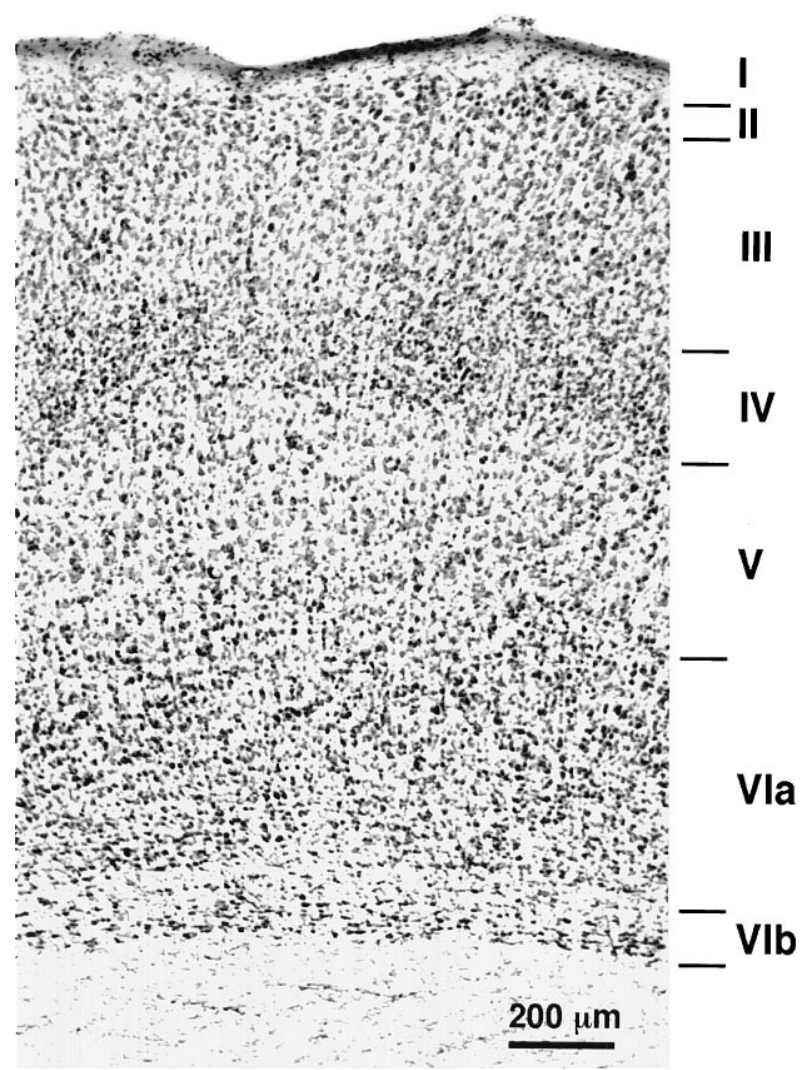

Figure 1. Frontal section of the rat primary somatosensory cortex stained with thionin. Note the light plexus of fibers that separates lamina VIa from lamina VIb.

glass micropipettes (tip diameter, 1-2 $\mu \mathrm{m}$ ) filled with a solution of potassium acetate or $\mathrm{KCl}(0.5 \mathrm{M})$ plus $1.7 \%$ biocytin (Sigma, St. Louis, $\mathrm{MO}$ ). In each animal up to four lamina VI cells (two in each hemisphere) of the somatosensory vibrissae area were labeled. The map of vibrissae representation published by Neafsey et al. (1986) was used to guide the injections. Using an angular approach of $30^{\circ}$, micropipettes penetrated perpendicularly the cortical surface $2-4 \mathrm{~mm}$ behind the bregma and $\sim 5.5$ mm lateral to the midline. Labeling attempts were made at depths ranging from 1.6 to $2.0 \mathrm{~mm}$.

Neural activities in layer VI were greatly reduced under anesthesia. To detect the presence of silent cells, a small depolarizing current pulse $(0.1$ $\mathrm{nA}$ ) was injected through the micropipette at $2 \mathrm{~Hz}$. When bridge imbalance occurred, a steady depolarizing current of increasing intensity (up to $8 \mathrm{nA}$ ) was applied. In about half of the cases a nearby silent unit could be activated. The micropipette was then advanced until it became possible to modulate firing with currents of 1-4 nA. At this point spike amplitude usually reached 5-10 mV. Labeling was made by applying depolarizing current pulses (200 msec duration, 50\% duty cycle) for periods of 10-20 min under continuous electrophysiological monitoring of cell firing.

Histology and cell reconstruction. After a survival period of 3-6 hr, animals were given an overdose of anesthetic and perfused with $0.9 \%$ $\mathrm{NaCl}$ followed by a fixative containing $4 \%$ paraformaldehyde and $0.5 \%$ glutaraldehyde in PBS (0.1 M, pH 7.4). Brains were cryoprotected with $30 \%$ sucrose and were sectioned coronally at $70 \mu \mathrm{m}$ on a freezing microtome. Sections were collected in PBS, and after several rinses in PBS, they were incubated for $12 \mathrm{hr}$ in the Vectastain $\mathrm{ABC}$ reagent in a PBS solution containing Triton X-100 (0.1\%). After two rinses in PBS and two rinses in a Tris-[hydroxymethyl]aminomethane buffer saline (TBS; $0.05 \mathrm{M}, \mathrm{pH}$ 7.6), sections were reacted with a TBS solution containing diaminobenzidine $(0.05 \%), \mathrm{H}_{2} \mathrm{O}_{2}(0.003 \%)$, and nickel ammonium sulfate $(0.3 \%)$. Finally, sections were mounted on gelatin-coated slides, dehydrated in alcohols, cleared in toluene, and coverslipped without counterstaining.

Cells and their axonal processes were drawn with a camera lucida using $25 \times$ or $40 \times$ objectives. The axonal fields of labeled neurons were also mapped at low magnification to locate their position in corresponding plates of the atlas of Paxinos and Watson (1986). Biocytin histochemistry, especially with the ABC Elite kit, often produced background staining that allowed delineation of cortical laminae and thalamic nuclei. When the borders of cortical laminae remained uncertain, coverslips were removed, and sections were counterstained with thionin. Although the quality of the counterstaining was generally adequate to visualize the granule cell layer and sublamina VIb, the upper border of lamina VI often remained difficult to determine.

\section{RESULTS}

\section{Cytoarchitectonic divisions of lamina VI}

Measurements made in Nissl preparations of the rat brain reveal that, regardless to the frontal plane of the sections, lamina VI occupies about one-third of the cortical thickness in the parietal region (Fig. 1) (Zilles, 1985; also see the atlas of Paxinos and

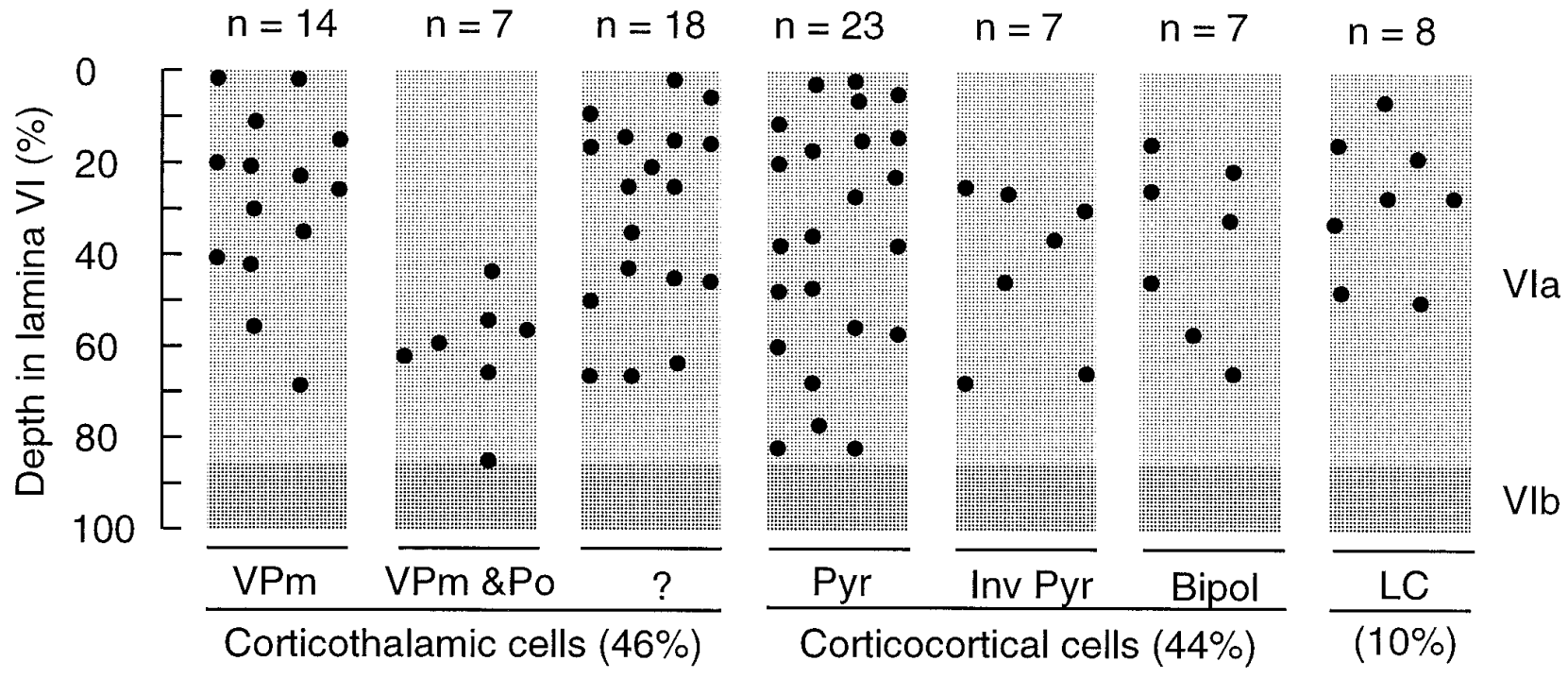

Figure 2. Distribution within lamina VI of the cortical barrel field of three classes of cells labeled juxtacellularly with biocytin. The class of CT cells is subdivided according to the projection site of the axons in the thalamus, and corticocortical cells are grouped according to the morphology of their dendritic trees. Pyr, Pyramidal-shaped cells; Inv Pyr, inverted pyramidal cells; Bipol, bipolar spiny neurons; LC, local circuit cells. 



Figure 3. Photomicrographs of a CT cell labeled juxtacellularly with biocytin. The location of this VPm projecting cell in the upper part of layer VI is shown in $A$. The cell body, dendrites, and axonal branches are shown in $B$ at a higher magnification. $C, D$, Terminations present along local axon collaterals in layers VI $(C)$ and IV $(D)$. 

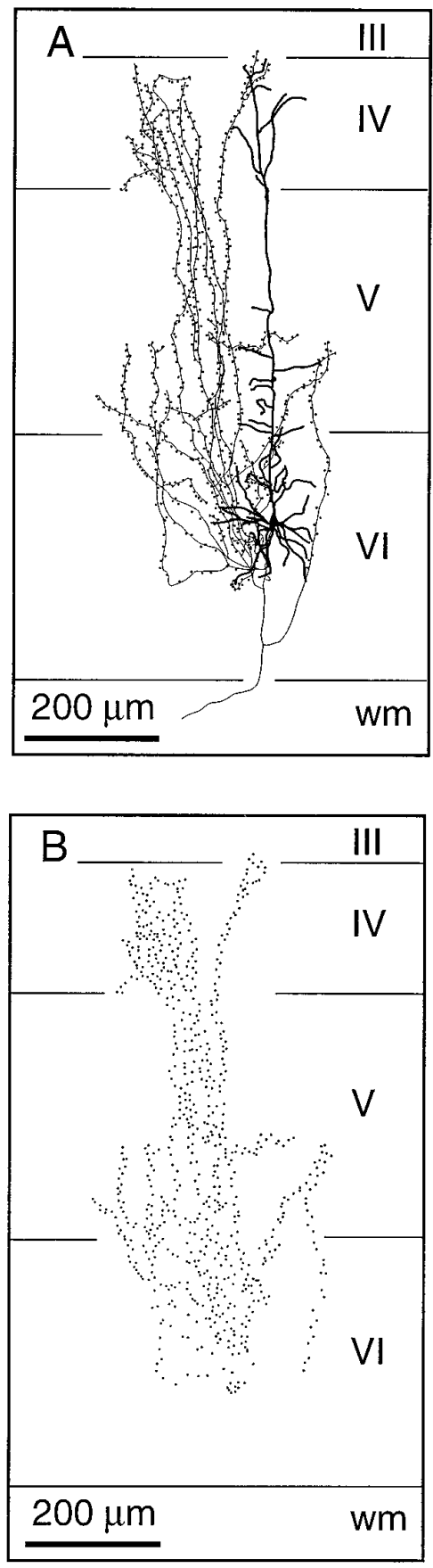


Figure 4. Laminar distribution of the axon collaterals of three CT neurons projecting to VPm. These cells $(A, C, E)$ are located in the upper half of lamina VI, and their apical dendrites terminate in layer IV. Note the columnar distribution of the axon collaterals. $B, D, F$, Distribution of terminations along the intracortical collaterals. $w m$, White matter.

Watson, 1986). Deep in lamina VI, close to the white matter, a light plexus of fibers about $100 \mu \mathrm{m}$ thick divides lamina VI in two parts, the upper part constituting lamina VIa and the lower narrow stratum of cells constituting lamina VIb. The present study bears exclusively on the axonal projections of cells located in lamina VIa. Some cells were also labeled in lamina VIb, but their number was too small and their morphology too diverse to achieve a comprehensive account.

\section{Data}

This report is based on the juxtacellular labeling of 84 cells in lamina V Ia of the rat primary somatosensory cortex. Forty-six percent of these neurons sent their axon to the thalamus, $44 \%$ projected to other cortical areas, and $10 \%$ projected locally, thus defining three broad classes of neurons: CT cells, corticocortical cells, and local circuit cells. The distribution of these neuronal populations within the depth of lamina VI is shown in Figure 2. Because the thickness of the cortex varies with the frontal plane of the sections, the location of each cell was normalized assuming that layer VI occupies one-third of the cortical thickness. The application of this criterion forced the rejection of 10 cells from our original sample, because these neurons were located either in layer V or in sublamina VIb. 

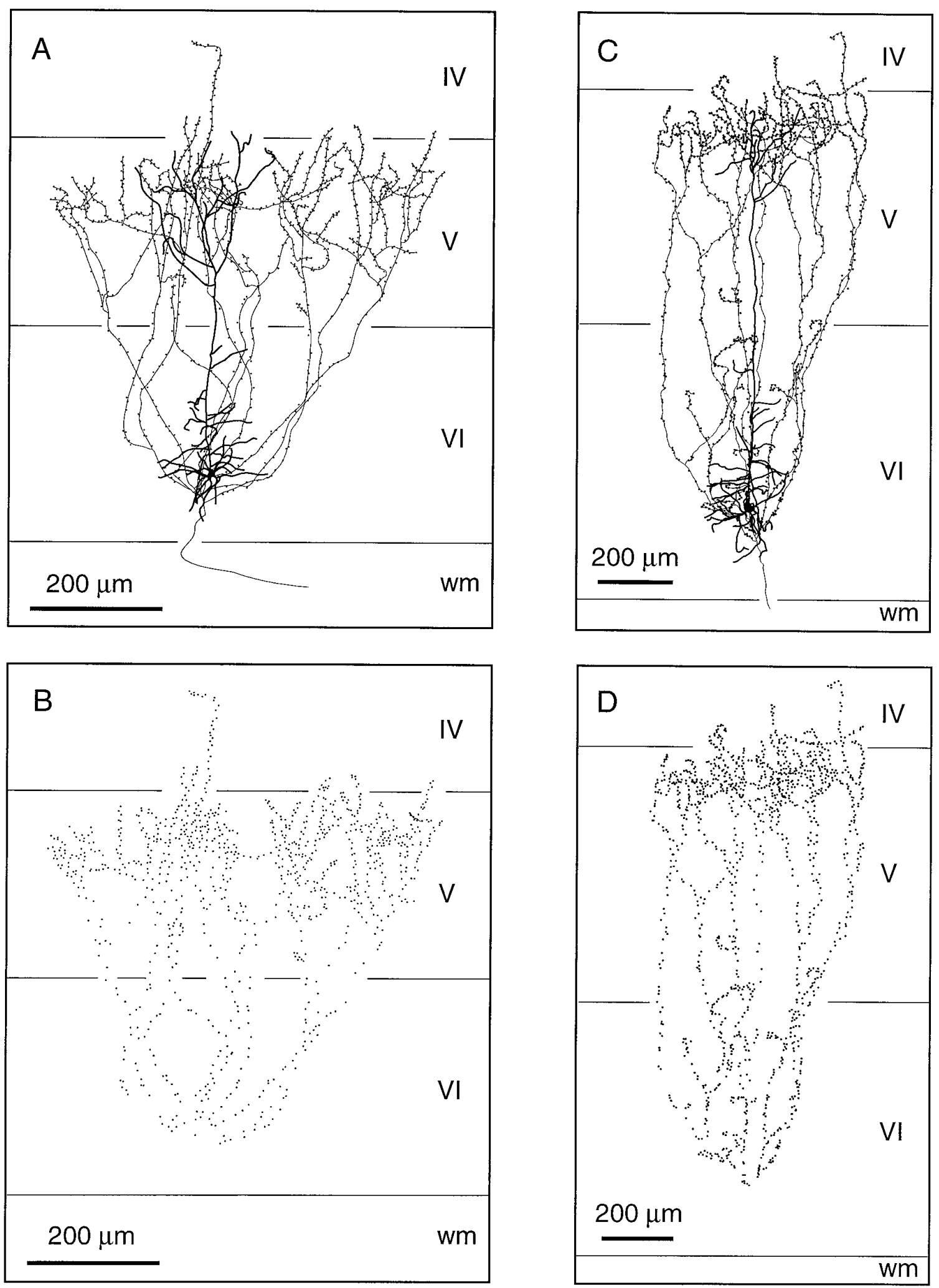

Figure 5. Laminar distribution of the axon collaterals of two CT neurons projecting to both VPm and Po. These cells $(A, C)$ are located in the lower half of lamina VI, and most of their dendritic or axonal branches terminate in lamina V. $B, D$, Distribution of terminations along the intracortical collaterals. $w m$, White matter. 

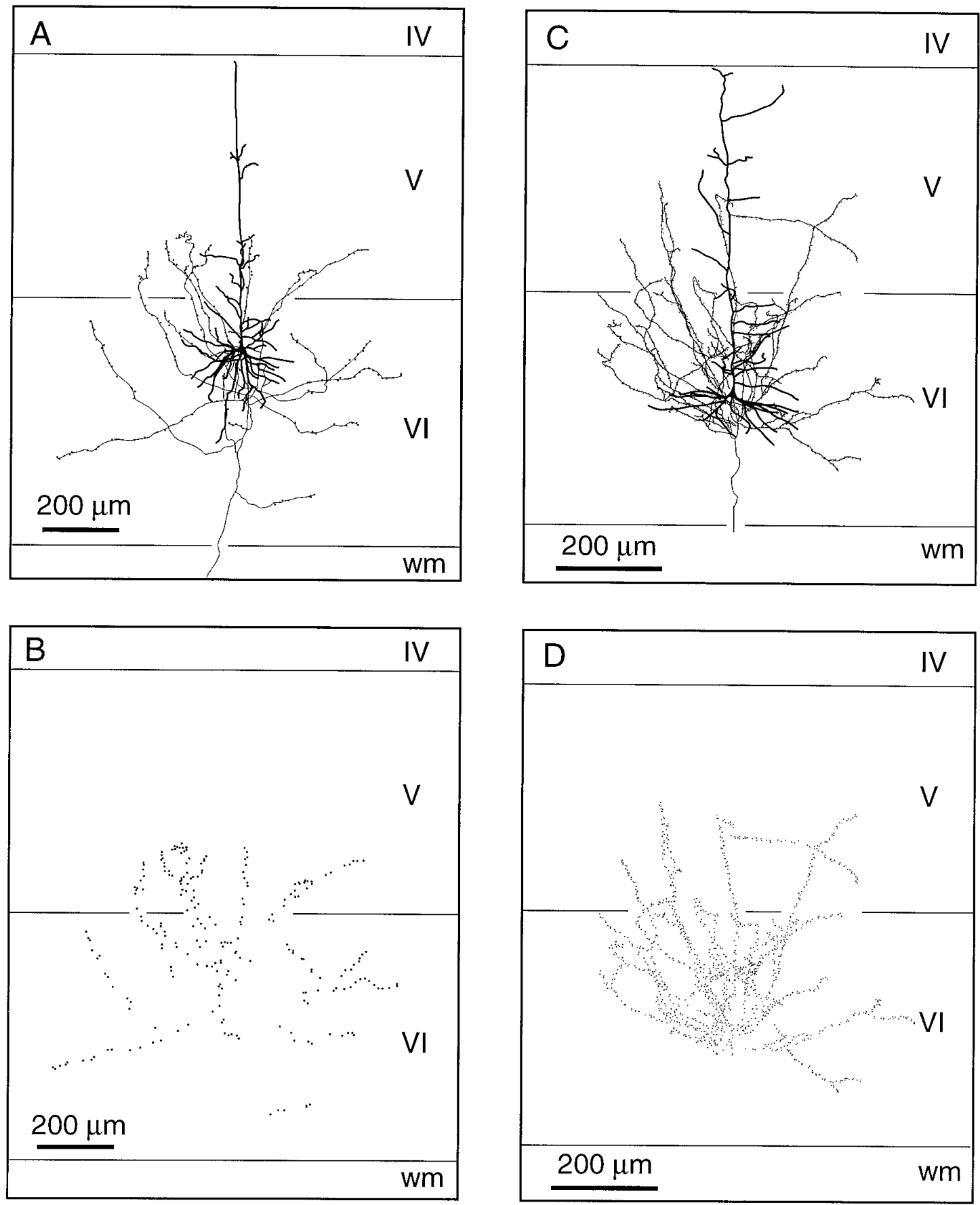

Figure 6. Laminar distribution of the axon collaterals of two CT neurons projecting to the ventral medial nucleus $(A)$ or to Po $(C)$. These cells do not give rise to long ascending branches and most of their terminations are restricted to lamina VI $(B, D)$. wm, White matter.

\section{Corticothalamic cells}

All cells classified as CT neurons $(n=39)$ had an axon that was followed at least as far as the thalamic reticular nucleus. Past this point, 14 cells projected to the ventral posteromedial nucleus (VPm), and seven projected to both VPm and the posterior group (Po; Fig. 2). The rest of the sample consisted of 16 cells, the axons of which were too faintly labeled to determine their nuclear targets, and two other cells that projected to Po alone or to the ventral medial nucleus.

The class of CT cells consists exclusively of small, spiny pyramids (base $\times$ height $\approx 10 \times 10 \mu \mathrm{m}$; mean volume, assuming a conical perikaryon, $262 \pm 95 \mu \mathrm{m}^{3}$ ) that are characterized by a skirt of tortuous basal dendrites radiating out from the cell body in all directions and by a short apical dendrite terminating in midcortical layers (Fig. 3). No significant difference in soma size or in axon diameter $(0.5-0.8 \mu \mathrm{m})$ was found between the two subclasses of cells that project to VPm alone or to both VPm and Po. Only one cell that projected to ventral medial nucleus had a larger cell body and a thicker axon (see below).

Corticothalamic cells that project to VPm alone are concentrated in the upper part of lamina VI (Fig. 2). Their apical dendrite gives off several side branches in the lower half of lamina 



Figure 7. Photomicrographs of four types of corticocortical cells labeled juxtacellularly with biocytin in lamina VI of the cortical barrel field. This montage shows a standard short pyramid $(A)$, an inverted pyramid $(B)$, a pyramidal cell with an apical dendrite oriented sideways $(C)$, and a bipolar spiny cell $(D)$. The pial surface is upward, and the scale bar in $D$ applies to all panels. 




Figure 8. Laminar distribution of the axon collaterals of a short pyramidal-shaped cell. This cell ramifies locally in lamina VI and gives off two axonal branches that project to the second somatosensory area. $B, C$, Enlarged view of the somatodendritic complex $(B)$ and the location of the cell in the histological section $(C)$. The frontal plane $(F)$ indicates the distance from the bregma. wm, White matter; Par1, parietal cortex, area 1; Par2, parietal cortex, area 2.

$\mathrm{V}$ and reaches lamina IV where it divides and terminates (Fig. $4 A, C, E)$. The axon of these neurons gives rise to three or four primary collaterals that take an upward direction and run vertically within a column of tissue about $200 \mu \mathrm{m}$ wide. Most collaterals branch sparsely in layer IV, and some invade the lower part of layer III. Terminations are present all along the course of the collaterals and appear as small swellings at the tip of fine stalks (Figs. 3C,D, $4 B, D, F)$. In the thalamus, the axon distributes branches in the thalamic reticular complex and forms a "rod-like" terminal field in VPm (for details, see Bourassa et al., 1995).

Corticothalamic cells that project to both VPm and Po are grouped into the lower half of lamina VIa. Their apical dendrite gives off short lateral branches in the upper half of layer VI and ascends to the upper part of layer $\mathrm{V}$ where it divides and terminates (Figs. 5A,C). Three to four collaterals depart from the main axon and head for the upper part of layer $\mathrm{V}$ where they form a lace-like plexus. As shown in Figure 5, the axonal collaterals of this group of CT cells occupy a wider cortical territory. Although this is not apparent in the drawing shown in Figure $5 C$, this cell has collaterals that span for about $800 \mu \mathrm{m}$ along the rostrocaudal axis. Again, terminations are observed in all layers along the course of the axonal branches (Figs. $5 B, D$ ). In the thalamus, CT cells that project to VPm and Po distribute branches in the thalamic reticular complex, but the terminal fields in VPm and Po were too faintly labeled to be fully reconstructed (but see Bourassa et al., 1995).

Two well labeled CT cells differ from the above descriptions. The one shown in Figure $6, A$ and $B$, has a larger soma $\left(500 \mu \mathrm{m}^{3}\right)$ and a thicker axon $(\sim 2 \mu \mathrm{m})$. In the thalamus, the axon of this cell arborizes profusely in the rostrolateral part of the reticular complex and continues its course ventralward to ramify in the ventral medial nucleus. The other cell shown in Figure $6, C$ and $D$, 


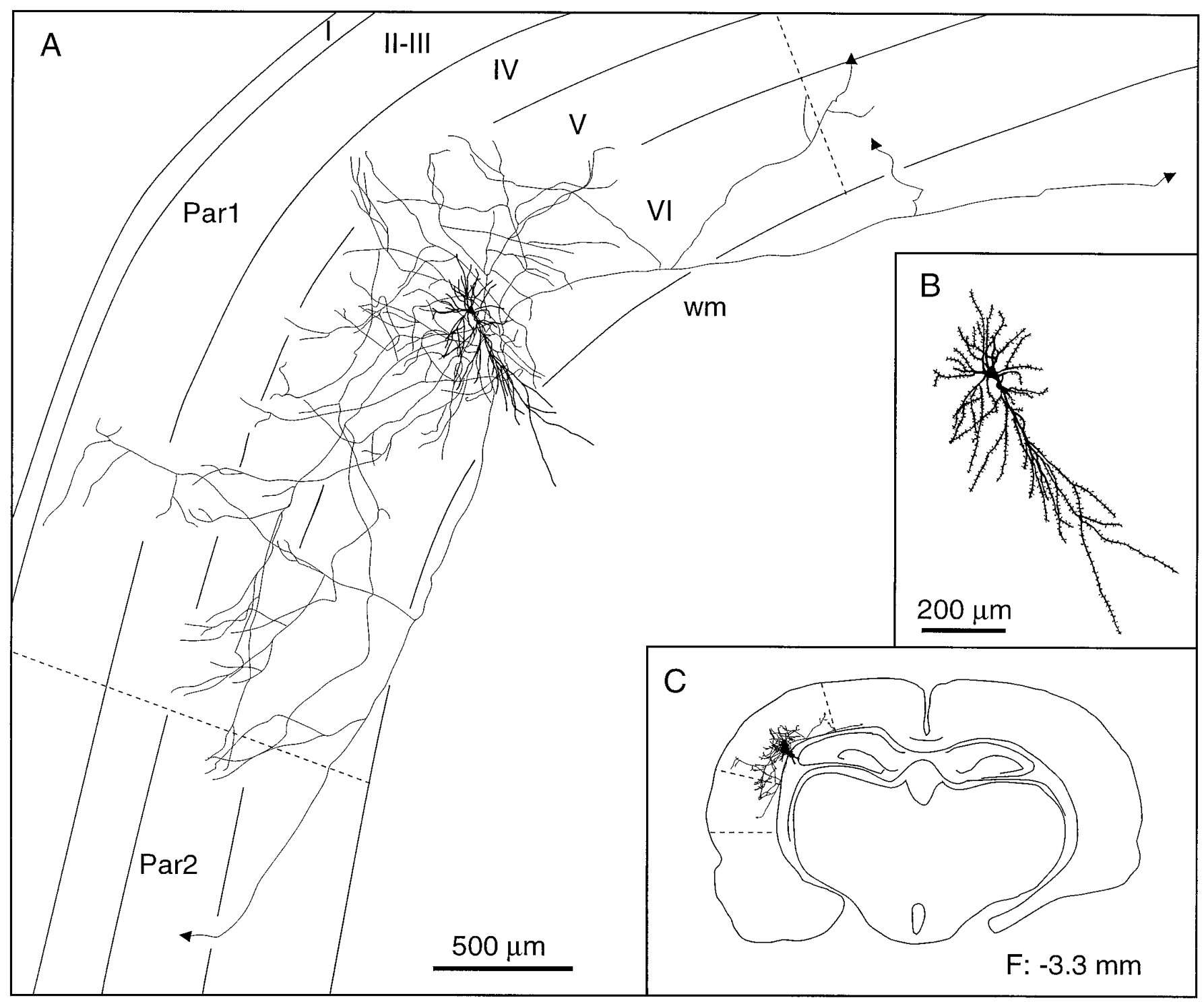

Figure 9. Laminar distribution of the axon collaterals of an inverted pyramidal cell. In addition to its local ramifications in laminae V and VI, this cell projects to the second somatosensory area and also sends a branch toward the motor cortex. $B$, $C$, Enlarged view of the somatodendritic complex $(B)$ and the location of the cell in the histological section $(C)$. The frontal plane $(F)$ indicates the distance from the bregma. wm, White matter; Parl, parietal cortex, area 1; Par2, parietal cortex, area 2.

projects to the inner tier of the thalamic reticular nucleus and to Po. These two CT cells have an apical dendrite that terminates in the upper part of layer $\mathrm{V}$, and their axonal collaterals spread obliquely in layer VI and in the lower part of layer $\mathrm{V}$, forming terminal boutons along their way (Fig. 6B,D).

\section{Corticocortical cells}

The class of corticocortical cells is composed of three histological types that are distributed throughout lamina VIa: short pyramidal cells, inverted or modified pyramids, and spiny bipolar cells. The most numerous corticocortical neurons have small, pyramidal-shaped somata (volume of the soma, $285 \pm 95 \mu \mathrm{m}^{3}$ ) and a short apical dendrite. They resemble CT neurons (compare Figs. $3 B, 7 A$ ), but many display less tortuous, more radiating basal dendrites that give them a star-like appearance (Fig. 8). It is thus possible that subgroups exist among this population of cells. Nonetheless, these short pyramidal cells have in common a descending axon that gives off 4-10 branches which form in the infragranular layers a field of loosely organized collaterals bearing varicosities and pedunculated boutons. One to three of these branches course tangentially deep in lamina VI or into the subcortical white matter to reach the second somatosensory area, the motor cortical areas, or the corpus callosum.

The group of inverted or modified pyramids includes five cells having one or two long dendrites that descend into the white matter and two other cells with an apical dendrite oriented parallel to the pia (Fig. $7 B, C$ ). The soma of these cells has a volume of $338 \pm 170 \mu \mathrm{m}^{3}$. Inverted pyramids arborize widely in layers $\mathrm{V}$ and VI and send one or two axonal branches to the second somatosensory cortex and/or to the motor cortex (Fig. 9). The two cells with a tangential apical dendrite arborized more profusely in laminae IV and VI, and they also sent axonal branches to the second somatosensory or motor cortices (Fig. 10).

Spiny bipolar cells are characterized by two long, vertically oriented dendrites emerging at the opposite poles of a triangular 




Figure 10. Laminar distribution of the axon collaterals of a pyramidal cell with a tangentially oriented apical dendrite. This cell gives rise to local fields of terminations in laminae III-IV and VI and also sends an axonal branch to the second somatosensory area. $B$, $C$, Enlarged view of the somatodendritic complex $(B)$ and the location of the cell in the histological section $(C)$. The frontal plane $(F)$ indicates the distance from the bregma. wm, White matter; Par1, parietal cortex, area 1; Par2, parietal cortex, area 2.

or fusiform perikaryon (volume, $345 \pm 123 \mu \mathrm{m}^{3}$; see Fig. $7 D$ ). The axon of bipolar cells gives origin to a complex net of collaterals in the infragranular layers and to longer branches that project either to the second somatosensory area, to the motor cortical areas, or to the corpus callosum (Fig. 11).

In general, the local collaterals of all types of corticocortical cells are studded with varicosities and pedunculated boutons, except the main branches, which remain smooth as they travel toward their distant projection site.

\section{Local circuit cells}

The class of local circuit cells labeled in lamina VI of the primary somatosensory cortex comprises a single cell type characterized by a medium-size multipolar perikaryon (size $\sim 18 \mu \mathrm{m}$ ), smoothbeaded dendrites, and an axon that initially ascends and rapidly breaks up into a profusion of collaterals densely covered with varicosities (see Figs. 12, 13). Terminal fields spread around the cell body in laminae $\mathrm{V}$ and $\mathrm{VI}$, but some branches may also extend into layer IV. These neurons also have in common an eccentric axonal branch that runs sideways for 700-800 $\mu \mathrm{m}$ at the frontier of laminae V and VI (Fig. 13, arrows). As a rule, local circuit cells were found in the upper half of layer VI, and they fired thin, brisk spikes during juxtacellular current injection.

\section{DISCUSSION}

Two main conclusions can be drawn from the present study. First, the architecture of the dendritic tree and the spread of the intracortical axonal arbor of CT cells are related to their projection target in the thalamus. Second, lamina VI of the rat primary somatosensory area contains a large number of neurons that, despite their apparent morphological diversity, are all involved in corticocortical relationships.

In our sample of cells labeled in lamina VIa of the cortical barrel field, CT cells account for $46 \%$ of the cellular population, a figure that agrees with counts made in the cat visual cortex, in which it was estimated that $\sim 50 \%$ of lamina V I cells project to the thalamus (Gilbert and Kelly, 1975). Yet, none of these CT cells collateralize to other cortical fields. The population of corticocortical cells represents $44 \%$ of the sample of cells stained in lamina VIa. Considering that a large number of cells in lamina VIb may also project to other cortical areas (Clancy and Cauller, 1996), lamina VI, as a whole, appears 


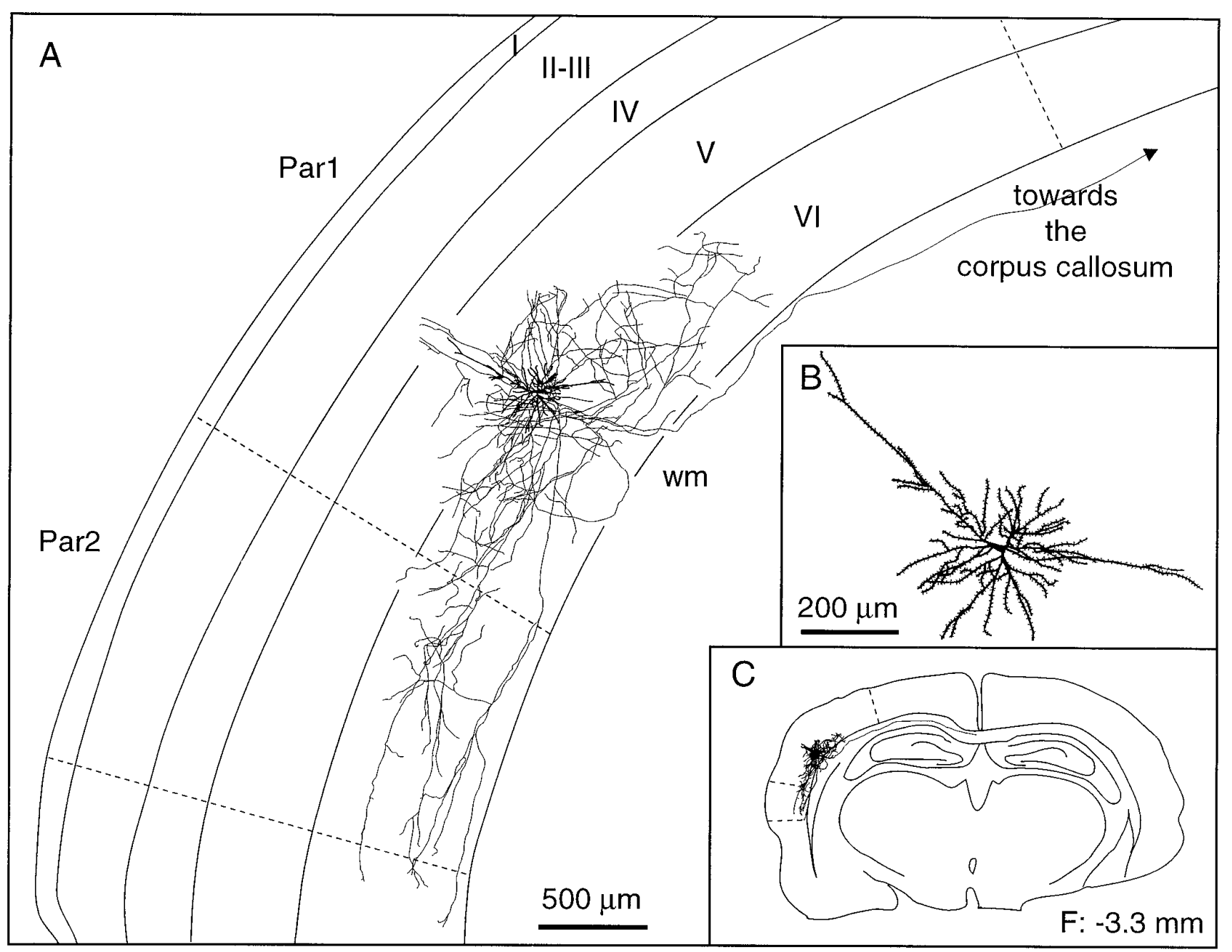

Figure 11. Laminar distribution of the axon collaterals of a spiny bipolar cell. This cell ramifies abundantly in lamina VI of the primary and second somatosensory areas. It also gives rise to a long axonal branch that runs into the corpus callosum. $B$, $C$, Enlarged view of the somatodendritic complex $(B)$ and the location of the cell in the histological section $(C)$. The frontal plane $(F)$ indicates the distance from the bregma. wm, White matter; Par1, parietal cortex, area 1; Par2, parietal cortex, area 2.

as a merging network for corticothalamic and corticocortical communications.

\section{Topographical organization of CT projections}

When neuronal connections are studied at a single-cell level, they disclose a surprisingly high degree of topographic specificity, which is often masked by the labeling of even small pools of cells. The present study shows that the juxtacellular labeling of single cells in vivo can be a very efficient neuroanatomical tool to decipher the fine organization of neural systems. Its application to the study of CT neurons has provided more detailed information about the organization of their axonal projections in the thalamus and cortex.

\section{In the thalamus}

After Phaseolus vulgaris leucoagglutinin injections restricted to the dimension of a single-barrel column in the mouse somatosensory cortex, anterograde labeling in VPm consists of a dense zone of terminations approximating the diameter of a barreloid and of an elongated curvilinear spread of terminations, which, in horizontal sections, forms a comet tail-like projection pattern (Hoogland et al., 1988, their Fig. 1). This result was interpreted as indicating that the $\mathrm{CT}$ projection of a single barrel contacts a series of thalamic barreloids representing an arc of vibrissae. More recently, Land and colleagues (1995) disclosed the precise three-dimensional architecture of barreloids in the adult rat thalamus and provided convincing evidence of an one-to-one relationship between individual barrel columns and thalamic barreloids (Land et al., 1995, their Fig. 7). This conclusion, however, was drawn from tracer injections, which, albeit confined to a single barrel column, did not involve the deep part of lamina VI.

In a previous study we reported that two types of CT fibers innervate the rat VPm (Bourassa et al., 1995). The first type, which arises from cells in the upper part of lamina VI, projects only to VPm. The question arises of whether the rod-like configuration of the terminal fields of these CT fibers is coextensive with the three-dimensional geometry of a barreloid. As shown by Land et al. (1995), barreloids extend through VPm from dorsomedial to ventrolateral, curving either rostrally or caudally. In light of this topographical information, we carefully analyzed the present material and reexamined our previous data to reach the conclusion that the terminal field of this first type of CT fiber is indeed comparable to the dimension and orientation of a tha- 

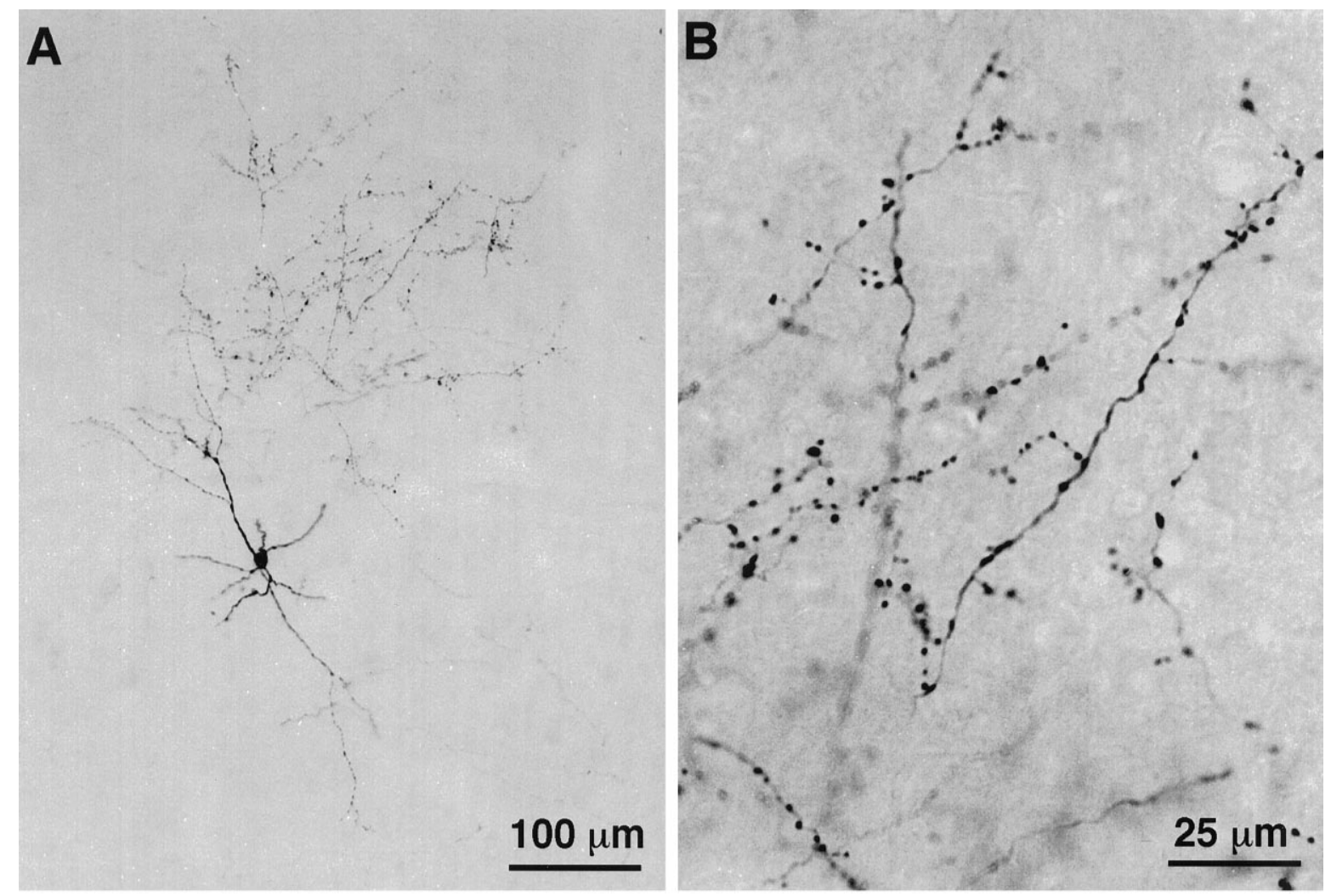

Figure 12. Photomicrographs of a basket cell labeled juxtacellularly with biocytin in layer VI of the cortical barrel field. The cell is shown at low magnification in $A$, and the aspect of the terminal field is shown at a higher magnification in $B$.

lamic barreloid. On the other hand, the second type of CT fiber, which arises from cells in the lower part of lamina VI, terminates in both VPm and Po. In VPm, the projection is light but exhibits a high degree of rostrocaudal streaming (1-1.5 mm; see Bourassa et al., 1995), leaving little doubt that the terminal field extends across a series of barreloids. It thus seems possible that the actual projection pattern of CT fibers in the rodent VPm implies a dual organization. The differential labeling of both types of CT axons combined with cytochrome oxidase histochemistry should settle this issue.

\section{In the cortex}

In the cortex, the distribution of the axonal collaterals of both types of CT cells seems to replicate the thalamic organization. Corticothalamic cells projecting to a single thalamic barreloid distribute their collaterals within a narrow column of tissue approximating the size of a barrel $(\sim 250 \mu \mathrm{m})$. It is thus likely that these cells contact only the neurons located within their own barrel column. Accordingly, one would expect that, among these CT cells, those located at the edge of a column would give rise to an eccentric field of collaterals to contact other neurons residing in the same barrel column. Such cases were indeed observed, as shown in Figure $4 A$. On the other hand, CT cells that project to both VPm and Po give rise to a more widespread net of collaterals that likely extend across two or three adjacent barrel columns $(\sim 800 \mu \mathrm{m})$. Because the present study did not use cytochrome oxidase histochemistry and electrophysiological recordings to generate a functional map of the barrel field, it is not possible to determine whether these adjacent barrels represent whiskers situated within the same arc or row of the mystacial pad.

The laminar distribution of the apical dendrites and axonal ramifications of both types of CT cells seems congruent with the laminar patterns of connections established by VPm and Po afferents in the cortical barrel field. Corticothalamic cells that project only to VPm have apical dendrites and axon collaterals that reach to layer IV, where the bulk of VPm afferents terminate (Wise and Jones, 1978; Jansen and Killackey, 1987). In contrast, CT cells that project mainly to Po have apical dendrites and axon collaterals that arborize in layer $\mathrm{Va}$, which is the main termination site of Po afferents in the barrel field (Herkenham, 1980; Lu and Lin, 1993). These anatomical features suggest that the principle of reciprocity of connections between the cortex and thalamus may also apply to some extent to the laminar distribution of the axonal and dendritic branches of CT cells in the cortical barrel field. Corticothalamic cells would contact, by means of their collaterals, those cortical neurons that are the targets of the thalamocortical cells they innervate. Interestingly, data obtained in the cat visual cortex also revealed two types of CT cells with morphological features similar to those observed in the rat barrel field (Katz, 1987). Whether these differences are related to the projection sites of these neurons in the lateral geniculate nucleus and/or in the lateral dorsal-pulvinar complex remains an open issue (see Bourassa and Deschênes, 1995).

The recurrent collateral input of CT neurons to layer IV stands as a prominent feature of most wiring diagrams of the cortical organization of primary sensory cortices. Mapping the intracortical terminations of CT cells in the cortical barrel field, however, revealed that boutons are distributed all along the axonal branches as they ascend through the infragranular layers. This observation is in line with the electron microscopic results of White and Keller (1987) showing that the local axonal collaterals 

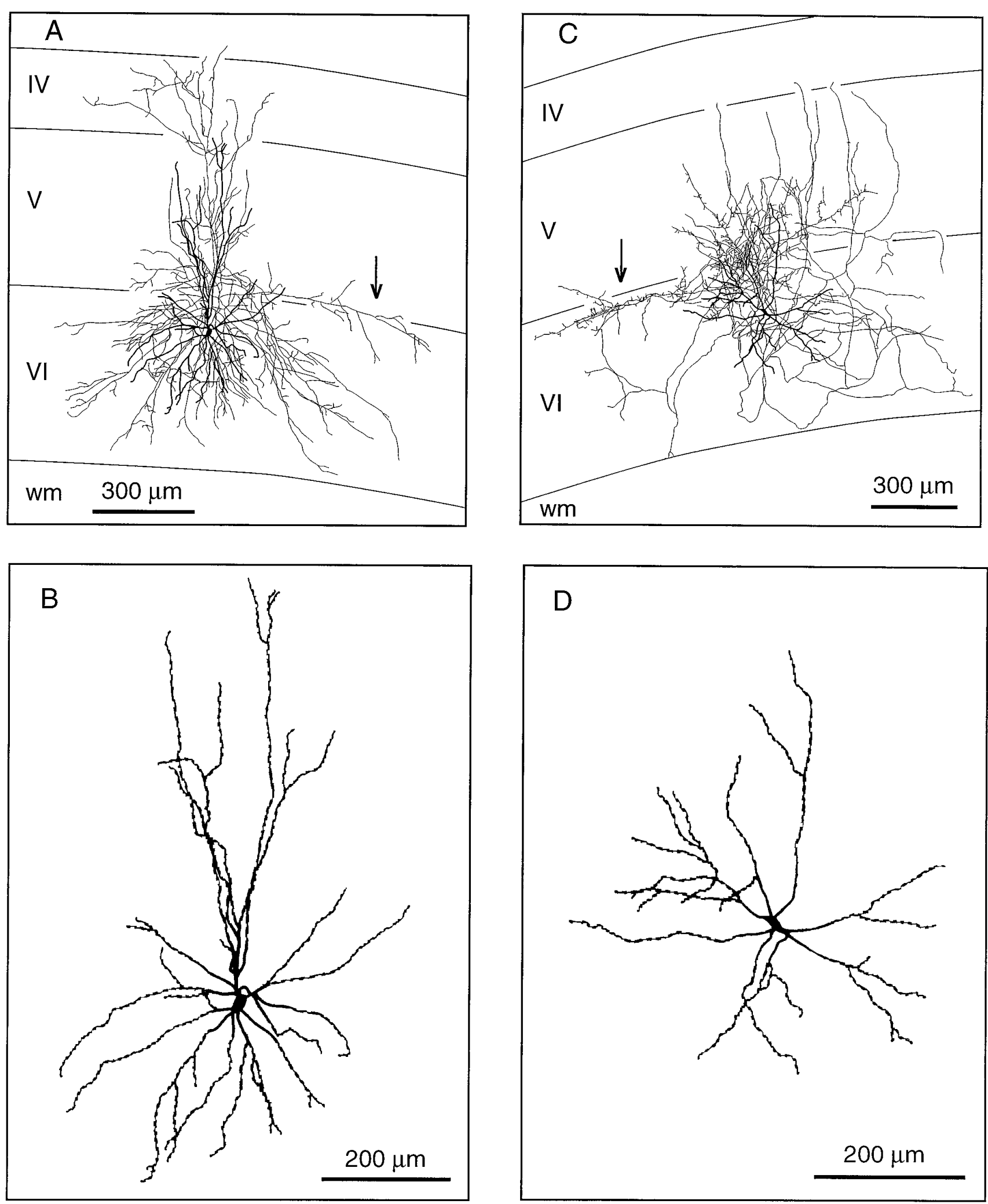

Figure 13. Drawings of two basket cells located in lamina VI of the primary somatosensory cortex. The laminar distribution of axon collaterals is shown in $A$ and $C$. Arrows point to the eccentric axonal branches coursing at the frontier of layers V and VI. The smooth varicose aspect of the dendrites is depicted in $B$ and $D$. wm, White matter. 
of CT cells in the mouse somatosensory cortex make synapses throughout layers IV-VI with the spiny dendrites of other pyramidal cells and, more frequently, with the smooth dendrites of multipolar interneurons. Accordingly, intracellular recordings in vitro have shown that, unless inhibitory transmission is blocked by GABA antagonists (Stratford et al., 1996), inhibition rather than excitation is the main postsynaptic effect observed in granule cells after stimulation of layer VI pyramids (Hirsch, 1995).

\section{Corticocortical cells}

Although lamina VI cells that give rise to corticocortical connections have different morphologies, they nevertheless share basic anatomical and electrophysiological similarities with the classic pyramidal cell type. Normally oriented, inverted, or "modified" pyramids and bipolar cells have spiny dendrites that extend differently in infragranular layers. They may thus receive different sets of inputs, but their axonal projections, at least to the extent that they were stained, do not permit classification of them into different functional subclasses. Electrophysiological recordings in vitro were also unable to establish a clear relationship between cell morphology and intrinsic electrophysiological properties among these cell types (van Brederode and Snyder, 1992). The apparent diversity suggested by the orientation of the dendritic trees may therefore reflect developmental changes rather than a true differentiation into distinct cellular phenotypes.

In primary sensory cortical areas, lamina VI is not usually considered a major source of corticocortical projections. It comes as a surprise that $44 \%$ of lamina VI cells of the cortical barrel field project to the second somatosensory area or to motor cortical regions. These corticocortical connections have been well established in rats, but most were seen to arise from layers II, III, and Va with a minor contribution from lamina VI (Donoghue and Parham, 1983; Isseroff et al., 1984; Koralek et al., 1990; Miyashita et al., 1994). The small number of corticocortical cells found in lamina VI in these retrograde transport studies could result from the fact that the injections sites did not span across the whole thickness of the cortex and/or from the sparse arborization of lamina VI afferents in these regions. A recent study using fast blue as a retrograde tracer reported that a large number of cells in lamina $\mathrm{VIb}$ also project to other cortical regions, but that these cells remained unlabeled after similar injections of wheat germ peroxidase conjugate (Clancy and Cauller, 1996). This observation not only confirms that all tracers are not equally effective at revealing neuronal connections (Trojanowski et al., 1982), but, more fundamentally, it indicates that lamina VI, as a whole, might be more implicated in corticocortical connections than what was thought previously.

\section{Local circuit cells}

Local circuit cells in lamina VI are surely not reducible to the single cell type that was labeled in the present study, because other interneuronal types have also been disclosed in the deep cortical layers by Golgi impregnations (Tömböl, 1984). Labeled interneurons have a larger cell body than the other cell types, a multipolar shape, smooth and varicose dendrites, and a dense plexus of axonal branches. Such features are characteristic of the cortical basket cells (Jones and Hendry, 1984). In Golgi preparations, these neurons were reported as one of the more common variety of nonpyramidal cell stained and to be among the largest local circuit cells (Peters and Jones, 1986). Basket cells are found in the upper half of layer VI, and their dendrites radiate locally and ascend in layer V. They are thus in an especially favorable position to receive contacts from VPm afferents and from the ascending collaterals of CT neurons. Available evidence shows that the nonspiny multipolar cells of the cortical barrel field are GABAergic (Chmielowska et al., 1986; Keller and White, 1986) and represent one of the main targets of the axonal collaterals of CT cells (White and Keller, 1987). The large number of connections made in lamina VI by the basket cells suggests that they take part in a powerful, recurrent inhibitory network that directly controls the firing of CT cells.

\section{REFERENCES}

Bourassa J, Deschênes M (1995) Corticothalamic projections from the primary visual cortex in rats: a single cell study using biocytin as an anterograde tracer. Neuroscience 66:253-263.

Bourassa J, Pinault D, Deschênes M (1995) Corticothalamic projections from the cortical barrel field to the somatosensory thalamus in the rat: a single fiber study using biocytin as an anterograde tracer. Eur J Neurosci 7:19-30.

Chmielowska J, Stewart MG, Bourne RC, Hamori J (1986) $\gamma$-Aminobutyric acid immunoreactivity in mouse barrel field: a light microscopical study. Brain Res 368:371-373.

Clancy B, Cauller LJ (1996) Widespread projections from layer VII (VIb mature subplate) neurons to layer I in adult rat cortex revealed selectively with fluorescent tracers. Soc Neurosci Abstr 22:107.

Donoghue JP, Parham C (1983) Afferent connections of the lateral agranular field of the rat motor cortex. J Comp Neurol 217:390-404.

Gilbert CD, Kelly JP (1975) The projection of cells in different layers of the cat's visual cortex. J Comp Neurol 163:81-106.

Herkenham M (1980) Laminar organization of thalamic projections of the rat neocortex. Science 207:532-534.

Hirsch JA (1995) Synaptic integration in layer IV of the ferret striate cortex. J Physiol (Lond) 483:183-199.

Hoogland PV, Welker A, Van der Loos H, Wouterlood FG (1988) The organization and structure of the thalamic afferents from the barrel cortex in the mouse; a PHA-L study. In: Cellular thalamic mechanisms (Bentivoglio M, Spreafico R, eds), pp 151-162. Amsterdam: Excerpta Medica.

Isseroff A, Schwartz ML, Dekker JJ, Goldman-Rakic P (1984) Columnar organization of callosal and associational projections from rat frontal cortex. Brain Res 293:213-223.

Jansen KF, Killackey HP (1987) Terminal arbors of axons projecting to the somatosensory cortex of the adult rat: 1 . The normal morphology of specific thalamocortical afferents. J Neurosci 7:3529-3543.

Jones EG (1985) The thalamus. New York: Plenum.

Jones EG, Hendry SHC (1984) Basket cells. In: Cerebral cortex, Vol 1 (Jones EG, Peters A, eds), pp 309-336. New York: Plenum.

Katz LC (1987) Local circuitry of identified projection neurons in cat visual cortex brain slices. J Neurosci 7:1223-1249.

Keller A, White EL (1986) Distribution of glutamic acid decarboxilaseimmunoreactive structures in the barrel region of mouse somatosensory cortex. Neurosci Lett 66:245-250.

Koch C, Sherman SM (1988) The control of retinogeniculate transmission in the mammalian lateral geniculate nucleus. Exp Brain Res 63:1-20.

Koralek KA, Olavarria J, Killackey HP (1990) Areal and laminar organization of corticocortical projections in the rat somatosensory cortex. J Comp Neurol 299:133-150.

Land PW, Buffer SA, Yaskovsky JD (1995) Barreloids in adult rat thalamus: three-dimensional architecture and relationship to somatosensory cortical barrels. J Comp Neurol 355:573-588.

Lévesque M, Gagnon S, Parent A, Deschênes M (1996) Axonal arborizations of corticostriatal and corticothalamic fibers arising from the second somatosensory area in the rat. Cereb Cortex 6:759-770.

Lu SM, Lin RC (1993) Thalamic afferents of the rat barrel cortex: a light- and electron-microscopic study using Phaseolus vulgaris leucoagglutinin as an anterograde tracer. Somatosens Mot Res 10:1-16.

Miller MW, Potempa G (1990) Number of neurons and glia in mature rat somatosensory cortex: effects of prenatal exposure to ethanol. J Comp Neurol 293:92-102.

Miyashita E, Keller A, Asanuma H (1994) Input-output organization of the rat vibrissal motor cortex. Exp Brain Res 99:223-232.

Neafsey EJ, Bold EL, Haas G, Hurley-Gius KM, Quirk G, Sievert CF, 
Terreberry RR (1986) The organization of the rat motor cortex: a microstimulation mapping study. Brain Res Rev 11:77-96.

Paxinos G, Watson C (1986) The rat brain in stereotaxic coordinates, Ed 2. Sydney, Australia: Academic.

Peters A, Jones EG (1986) Classification of cortical neurons. In: Cerebral cortex, Vol 1 (Jones EG, Peters A, eds), pp 107-122. New York: Plenum.

Pinault D (1996) Morpho-functional features of juxtacellularly labeled central neurons: a novel single-cell staining procedure performed in vivo under electrophysiological control. J Neurosci Methods $65: 113-136$.

Sherk H (1986) The claustrum and the cerebral cortex. In: Cerebral cortex, Vol 5 (Jones EG, Peters A, eds), pp 467-499. New York: Plenum.

Sherman SM, Guillery RW (1996) Functional organization of thalamocortical relays. J Neurophysiol 76:1367-1395.

Stratford KJ, Tarczy-Hornoh K, Martin AC, Bannister NJ, Jack JJB (1996) Excitatory synaptic inputs to spiny stellate cells in cat visual cortex. Nature 382:258-261.
Tömböl T (1984) Layer VI cells. In: Cerebral cortex, Vol 1 (Jones EG, Peters A, eds), pp 479-519. New York: Plenum.

Trojanowski JQ, Gonatas JO, Gonatas NK (1982) Horseradish peroxidase (HRP) conjugates of cholera toxin and lectins are more sensitive retrogradely transported markers than free HRP. Brain Res 231:33-50.

van Brederode JFM, Snyder GL (1992) A comparison of the electrophysiological properties of morphologically identified cells in layers $5 \mathrm{~B}$ and 6 of the rat neocortex. Neuroscience 50:315-337.

White EL, Keller A (1987) Intrinsic circuitry involving the local axon collaterals of corticothalamic projection cells in mouse Sm1 cortex. J Comp Neurol 262:13-27.

Wise SP, Jones EG (1978) Developmental studies of thalamocortical and commissural connections in the rat somatic sensory cortex. J Comp Neurol 178:187-208.

Zilles K (1985) The cerebral cortex of the rat: a stereotaxic atlas. Berlin: Springer.

Zilles K, Wree A (1995) Cortex: areal and laminar structure. In: The rat nervous system, Ed 2 (Paxinos G, ed), pp 649-685. New York: Academic. 